RESEARCH REPORT

\title{
Effects of marital transitions on changes in dietary and other health behaviours in US male health professionals
}

\author{
Patricia Mona Eng, Ichiro Kawachi, Garrett Fitzmaurice, Eric B Rimm
}

J Epidemiol Community Health 2005;59:56-62. doi: 10.1136/jech.2004.020073

See end of article for authors' affiliations

.....................

Correspondence to: Dr P M Eng, Ingenix Epidemiology, 275 Grove Street, Auburndale, MA 02466, USA; meng@ epidemiology.com

Accepted for publication 2 March 2004

\begin{abstract}
Study objective: To examine the effect of change in marital status on health behaviours among men. Design: Longitudinal study of repeated measures of marital status and health behaviours collected at four year intervals (1986-90; 1990-94).

Setting: US male health professionals.

Participants: 38865 men aged 40-75 in 1986.

Main results: Relative to men who stayed married over four years, men who became widowed increased their alcohol consumption. Men who become divorced or widowed experienced decreases in body mass index. Compared with men who remained unmarried, men who remarried exhibited increases in body mass index along with decreased physical activity. Becoming divorced or widowed was associated with decreased vegetable intake while remarriage was linked to greater consumption.

Conclusions: Marital termination may adversely affect health and dietary behaviours among men.
\end{abstract}

poorer diet, weight loss, decreased physical activity, and increases in smoking and alcohol intake. Conversely, entry into marriage would have an ameliorative effect on these lifestyle factors. We also compared trajectories of health practices among men who maintained their marital states. We predicted that men who remained unmarried (that is, divorced or widowed) would suffer more adverse trends than continuously married men. Using repeated measures of marital status as well as of dietary and other health behaviours, we sought to clarify the temporal relation between marital transition and change in health practices. By studying a number of health behaviours, the impact of marital transition on health may be more wholly understood.

\section{METHODS}

The health professionals follow up study

The health professionals follow up study is a longitudinal investigation of chronic disease among 51529 US male health professionals aged 40 to 75 years old in 1986. Cohort members are dentists $(58 \%)$, veterinarians $(20 \%)$, pharmacists $(8 \%)$, optometrists $(7 \%)$, osteopaths $(4 \%)$, and podiatrists $(3 \%)$. Baseline data on risk factors and medical history were obtained from the participants by mailed questionnaire. Every two years, follow up questionnaires have been sent to update information on risk factors and newly diagnosed diseases. Collection and analysis of data were approved by the Institutional Review Board at the Harvard School of Public Health. Additional details of the study have been published elsewhere. ${ }^{39}$

\section{Study population}

Between 1986 and 1994, 39731 men provided data on marital status for at least two consecutive time points spaced four years apart (for example, 1986, 1990 or 1994). Compared with non-respondents, respondents were similarly aged ( 54.8 versus 55.0 years) but more likely to be married in 1986 (91.4\% versus $86.2 \%, \mathrm{p}<0.001)$. Proportions of heavy drinkers were comparable between groups but respondents were less likely to smoke $(8.9 \%$ versus $12.0 \%, \mathrm{p}<0.001)$.

Abbreviations: $B M I$, body mass index; $F F Q$, food frequency questionnaire; MET, metabolic equivalent 


\begin{tabular}{|c|c|c|c|}
\hline & Married & Divorced & Widowed \\
\hline \multicolumn{4}{|l|}{ Demographics } \\
\hline Age, mean (SD), y & $54.9(9.8)$ & $51.4(8.5)$ & $63.7(8.2)$ \\
\hline \multicolumn{4}{|l|}{ Medical conditions } \\
\hline Hypertension, \% & 21.9 & 21.8 & 25.4 \\
\hline High serum cholesterol, \% & 12.9 & 13.1 & 9.5 \\
\hline Diabetes, \% & 2.9 & 2.9 & 4.1 \\
\hline Myocardial infarction, \% & 4.1 & 4.2 & 4.5 \\
\hline Stroke, \% & 0.7 & 0.6 & 0.6 \\
\hline Cancer excluding non-melanoma skin cancer, \% & 3.7 & 3.4 & 3.0 \\
\hline \multicolumn{4}{|l|}{ Health behaviours } \\
\hline Current smoker, \% & 8.7 & 16.1 & 13.5 \\
\hline Alcoholic beverages, mean (SD), servings/week* & $6.1(8.3)$ & $8.4(10.4)$ & $6.5(8.6)$ \\
\hline Body mass index, mean (SD), $\mathrm{kg} / \mathrm{m}^{2 *}$ & $25.5(3.1)$ & $25.2(3.1)$ & $25.3(4.3)$ \\
\hline Physical activity, mean (SD), METs/week* & $20.0(25.7)$ & $23.3(27.8)$ & $19.3(21.4)$ \\
\hline \multicolumn{4}{|l|}{ Dietary behaviour } \\
\hline \multicolumn{4}{|l|}{ Mean (SD), servings/week } \\
\hline \multicolumn{4}{|l|}{ Vegetables, fruits } \\
\hline $\begin{array}{l}\text { Vegetables* } \\
\text { Fruit** }\end{array}$ & $21.8(12.9)$ & $\begin{array}{l}19.4(12.8) \\
97(911\end{array}$ & $18.6(13.0)$ \\
\hline Fruit juices & $5.5(6.0)$ & $5.6(7.3)$ & $5.2(7.2)$ \\
\hline \multicolumn{4}{|l|}{ Meats, poultry, seafood, eggs } \\
\hline Red meats* ${ }^{*}$ & $4.4(3.4)$ & $3.9(3.5)$ & $4.0(3.0)$ \\
\hline Organ meats* ${ }^{*}$ & $1.5(2.5)$ & $1.7(2.6)$ & $1.6(2.4)$ \\
\hline Processed meats & $2.6(3.1)$ & $2.6(3.6)$ & $2.5(4.1)$ \\
\hline Poultry & $2.4(2.0)$ & $2.5(2.2)$ & $2.3(2.1)$ \\
\hline Fish and other seafood* & $2.7(2.4)$ & $3.0(2.9)$ & $2.8(2.5)$ \\
\hline Eggs* & $2.3(2.9)$ & $2.6(3.4)$ & $2.2(2.8)$ \\
\hline \multicolumn{4}{|l|}{ Dairy } \\
\hline High fat dairy products* & $6.3(7.1)$ & $6.9(7.9)$ & $7.6(9.8)$ \\
\hline Low fat dairy products* & $6.2(7.3)$ & $5.6(7.4)$ & $6.1(8.5)$ \\
\hline \multicolumn{4}{|l|}{ Breads, cereals, starches } \\
\hline Refined grains* & $8.1(7.4)$ & $7.0(7.0)$ & $7.1(7.4)$ \\
\hline Whole grains* & $7.8(9.0)$ & $7.9(9.7)$ & $6.6(8.2)$ \\
\hline Cold breakfast cereal ${ }^{*}$ & $2.9(3.4)$ & $2.4(3.0)$ & $2.6(3.0)$ \\
\hline Potatoes* ${ }^{*}$ & $2.3(2.0)$ & $1.9(1.9)$ & $2.0(2.4)$ \\
\hline Snacks* & $4.0(5.1)$ & $3.5(5.2)$ & $3.7(4.8)$ \\
\hline \multicolumn{4}{|l|}{ Sweets, baked goods, miscellaneous } \\
\hline Sweets and desserts ${ }^{*}$ & $8.1(9.0)$ & $6.7(8.6)$ & $7.7(10.2)$ \\
\hline Nuts & $3.5(5.0)$ & $3.6(5.8)$ & $3.9(5.8)$ \\
\hline \multicolumn{4}{|l|}{ Non-alcoholic beverages } \\
\hline $\mathrm{Teq}^{*}$ & $3.1(6.0)$ & $2.6(5.8)$ & $2.9(5.8)$ \\
\hline Coffee & $13.5(12.5)$ & $13.8(13.3)$ & $14.5(12.4)$ \\
\hline Low calorie beverages & $3.4(6.4)$ & $3.5(7.5)$ & $3.0(5.6)$ \\
\hline High sugar beverages* & $2.4(4.3)$ & $2.6(5.3)$ & $2.8(3.9)$ \\
\hline \multicolumn{4}{|l|}{ Mean (SD), frequency/week } \\
\hline \multicolumn{4}{|l|}{ Fried foods } \\
\hline Fried food at home* & $1.3(1.4)$ & $1.1(1.3)$ & $1.3(1.3)$ \\
\hline Fried food away from home ${ }^{*}$ & $1.1(1.3)$ & $1.3(1.5)$ & $1.2(1.3)$ \\
\hline
\end{tabular}

Mean physical activity levels were higher among the respondents while body mass index means were similar between the response groups. We excluded 65 subjects who experienced inconsistent transitions between consecutive time points. Because the cohort was middle aged to elderly, transitions from never married to married states were scarce; hence we excluded men who were single in $1986(\mathrm{n}=801)$. A total of 38865 men were included in the analyses.

\section{Marital status and marital transitions}

Subjects reported their current marital status on each biennial questionnaire. Marital status was categorised as follows: married, divorced (includes separated), and widowed. We assumed that marital status assessed in a particular year reflected marital status during the previous year. Because we hypothesised that incumbent marital status would have the largest impact on concurrent behaviour, we examined marital status at the same time as health behaviour (1986, 1990, or 1994). Thus, we focused on marital status change between two measured points, 1986 and 1990, or 1990 and 1994, and not on interim marital changes between two measured points (1986 and 1990). Marital transitions of interest included both terminations (change in status from married to divorced or married to widowed) and remarriage (divorced to married; widowed to married). Because we expected stronger associations for spousal death, becoming widowed or divorced were treated as separate events. Men who did not experience marital transition between 1986 and 1990, or 1990 and 1994 were categorised as having a stable marital history (consistently married or unmarried-including divorced and widowed) for the respective interval. Of the 38865 men included in these analyses, 33108 provided marital transition data for 1986, 1990, and 1994 while 5757 provided marital transition information for 1986 and 1990 only. During each of the four year intervals, about $90 \%$ of men remained married, $4 \%$ remained divorced, and $1 \%$ remained widowed while $2 \%$ became divorced, $1 \%$ became widowed, and $2 \%$ remarried. In terms of marital transitions, 1415 divorces, 851 spousal deaths, and 1468 remarriages occurred between 1986 and 


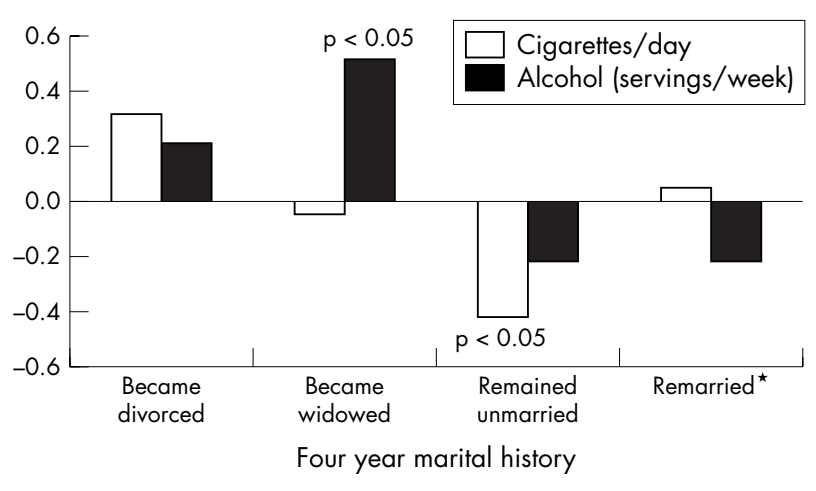

Figure 1 Multivariate mean change in cigarette and alcohol consumption for four year marital history relative to consistently married. Adjusted for age in 1986, time period (1986-90, 1990-94), body mass index $\left(\mathrm{kg} / \mathrm{m}^{2}\right.$ ), physical activity (METs/week), employment status (full time compared with part time, retired, or disabled), history of hypertension, diabetes, high serum cholesterol, diagnosis of myocardial infarction, stroke, and cancer (except non-melanoma skin cancer). Smoking (current compared with never or past smoker) and alcohol intake (servings/week) were mutually adjusted. Alcohol intake analysis was also adjusted for diagnosis of gastric/duodenal ulcer. Cigarette consumption analysis limited to ever smokers in 1986. All covariates except age were time varying. *Relative to consistently unmarried.

1990, or 1990 and 1994; these transitions were not mutually exclusive on the person level as, for example, a person could divorce between 1986 and 1990 and then remarry between 1990 and 1994.

Assessment of dietary and alcoholic beverage intake In 1986, 1990, and 1994, a semi-quantitative food frequency questionnaire (FFQ) was incorporated into the mailed questionnaire to assess frequency of intake of 131 foods including alcoholic beverages. The FFQ included questions about average consumption of each food during the previous year, with nine frequency response categories ranging from never or less than once per month to six times or more per day. All frequency categories were converted to units of servings per week (weekly intake). Specified serving sizes were based on natural portions (for example, a slice of bread, a cup of coffee) or weight and volume measures of standard

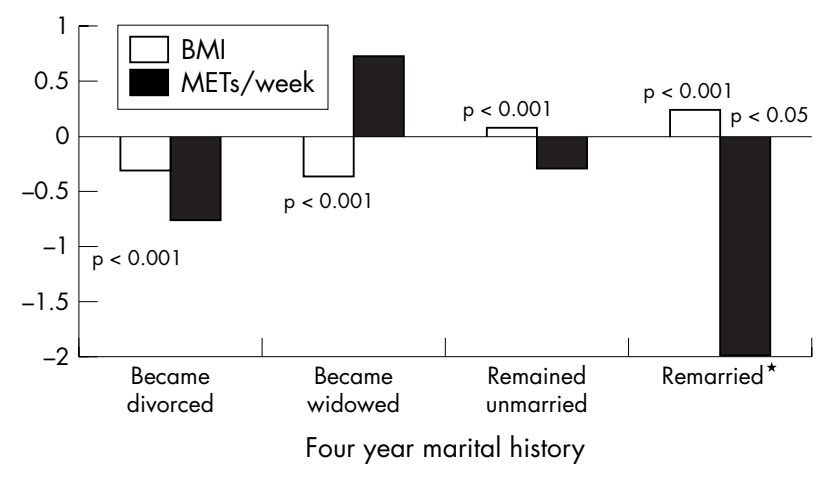

Figure 2 Multivariate mean change in BMl and physical activity for four year marital history relative to consistently married. Adjusted for age in 1986, time period (1986-90, 1990-94), smoking (current compared with never or past smoker), alcohol intake (servings/week), employment status (full time compared with part time, retired, or disabled), history of hypertension, diabetes, high serum cholesterol, diagnosis of myocardial infarction, stroke, cancer (except nonmelanoma skin cancer), gastric or duodenal ulcer, daily energy and total fat intakes. Body mass index $\left(\mathrm{kg} / \mathrm{m}^{2}\right)$ and physical activity (METs/week) were mutually adjusted. All covariates except age were time varying. *Relative to consistently unmarried. servings. We aggregated food items with similar nutrient value or usage into predefined food groups. ${ }^{40}$ Additional questions determined the frequency per week that fried foods were eaten at home, and away from home. Subjects whose reported daily energy intake was implausibly low $(<800 \mathrm{kcal} /$ day) or high $(>4200 \mathrm{kcal} /$ day $)(n=1227)$ or who left 70 or more food items blank $(\mathrm{n}=282)$ were excluded from dietary and alcohol analyses. Correlations between diet records and the food frequency questionnaire were 0.86, 0.76, 0.75, and 0.68 , for alcohol, cholesterol, saturated fat, and fibre, respectively. Further details on the reproducibility and validity of the FFQ have been published elsewhere. ${ }^{41} 42$ Change in consumption over time was calculated as the difference in average intake between two consecutive time points (1986 and 1990; 1990 and 1994).

\section{Assessment of other health behaviour outcomes}

Data on other health behaviours were obtained for each of the three years: 1986, 1990, and 1994. Subjects reported smoking status as never, past, or current, and if applicable, daily cigarette consumption. Body mass index (BMI) was calculated from self reported height and weight as weight in kilograms divided by height in metres squared. Height was ascertained in 1986, and assumed to be constant through 1994. Body weight in pounds was updated at each time point. In each of the three years, subjects also reported the average number of hours spent per week over the past year on the following activities: walking, stair climbing, jogging, running, lap swimming, bicycling and rowing (including stationary), calisthenics and racquet sports. These were multiplied by their associated energy expenditure requirements in metabolic equivalents (METs) and then summed to obtain total MET hours per week from combined leisure time and routine physical activity. Validity of self reported BMI and physical activity has been previously reported for this cohort. ${ }^{43}{ }^{44}$ In a subset of the cohort, the correlation coefficient between self reported and technician assessed weight was 0.97 while the correlation between diary and questionnaire scores for vigorous physical activity was $0.58 .{ }^{43}{ }^{44}$ Four year changes in cigarette consumption, BMI, and physical activity levels were calculated as the differences in means between 1986 and 1990, and 1990 and 1994.

\section{Data analyses}

We estimated the effect of four year marital history on corresponding change in health behaviours within individuals (for example, the effect of marital transition between 1986 and 1990 on behavioural change from 1986 to 1990). To estimate the effect of four year marital history on concurrent change in dietary and alcohol intake, daily cigarette consumption, BMI, and physical activity, multivariate linear regression was performed on repeated measures of these continuous outcomes. Adjusted time trends were obtained using residual maximum likelihood estimation, assuming an unrestricted covariance structure. We compared trajectories of men who changed their marital status with those of men who remained stable. For example, men who became widowed were compared with stably married men, while widowers who remarried were compared with widowers who did not remarry. Time trends of unmarried (divorced or widowed) men were contrasted with those of married men. Trends for the referent groups were allowed to vary over the two four year intervals to adjust for general time effects that may have been partially unique to our cohort. Specifically, questions regarding dietary and alcohol intake, and physical activity levels were slightly modified over the study period. Relative trends for four year marital histories were assumed to be constant over the two intervals. We combined groups of men with similar marital histories (for example, divorced or 
Table 2 Multivariate† mean change (SE) in dietary intake for four year marital history

\begin{tabular}{|c|c|c|c|c|}
\hline & $\begin{array}{l}\text { Married to } \\
\text { divorced }\end{array}$ & $\begin{array}{l}\text { Married to } \\
\text { widowed }\end{array}$ & $\begin{array}{l}\text { Remained } \\
\text { unmarried }\end{array}$ & Remarried \\
\hline \multicolumn{4}{|l|}{ Servings per week } & \\
\hline Vegetables & $-2.05(0.40)^{* * *}$ & $-2.91(0.52)^{\star * *}$ & $0.20(0.23)$ & $1.88(0.46)^{* * *}$ \\
\hline Fruits & $-0.59(0.25)^{*}$ & $-0.25(0.33)$ & $0.28(0.14)$ & $0.12(0.29)$ \\
\hline Fruit juices & $0.02(0.18)$ & $0.12(0.23)$ & $-0.003(0.10)$ & $-0.27(0.21)$ \\
\hline \multicolumn{5}{|l|}{ Meats, poultry, seafood, eggs } \\
\hline Red meats & $-0.33(0.10)^{\star * *}$ & $0.08(0.13)$ & $0.10(0.06)$ & $-0.08(0.11)$ \\
\hline Organ meats & $0.09(0.12)$ & $0.38(0.15)^{*}$ & $0.09(0.07)$ & $-0.14(0.13)$ \\
\hline Processed meats & $0.07(0.08)$ & $0.05(0.11)$ & $0.03(0.05)$ & $-0.03(0.10)$ \\
\hline Poultry & $-0.19(0.07)^{*}$ & $0.05(0.09)$ & $-0.07(0.04)$ & $0.19(0.08)^{*}$ \\
\hline Fish and other seafood & $-0.004(0.07)$ & $0.24(0.09)^{*}$ & $-0.01(0.04)$ & $-0.06(0.08)$ \\
\hline Eggs & $-0.03(0.07)$ & $-0.04(0.09)$ & $0.05(0.04)$ & $-0.14(0.08)$ \\
\hline \multicolumn{5}{|l|}{ Dairy } \\
\hline High fat dairy products & $0.11(0.20)$ & $0.25(0.26)$ & $-0.05(0.12)$ & $-0.32(0.23)$ \\
\hline Low fat dairy products & $-0.23(0.21)$ & $-0.48(0.27)$ & $-0.04(0.12)$ & $0.04(0.24)$ \\
\hline \multicolumn{5}{|l|}{ Breads, cereals, starches } \\
\hline Refined grains & $-0.61(0.23)^{*}$ & $-0.98(0.30)^{*}$ & $-0.11(0.13)$ & $0.84(0.26)^{*}$ \\
\hline Whole grains & $-0.28(0.27)$ & $-0.13(0.35)$ & $0.04(0.15)$ & $-0.03(0.30)$ \\
\hline Cold breakfast cereal & $-0.21(0.11)^{*}$ & $-0.24(0.14)$ & $-0.001(0.06)$ & $0.01(0.12)$ \\
\hline Potatoes & $-0.19(0.07)^{*}$ & $-0.36(0.08)^{\star \star *}$ & $0.02(0.04)$ & $0.13(0.07)$ \\
\hline Snacks & $-0.35(0.20)$ & $-0.30(0.26)$ & $0.23(0.11)^{*}$ & $-0.34(0.22)$ \\
\hline \multicolumn{5}{|c|}{ Sweets, baked goods, miscellaneous } \\
\hline Sweets and desserts & $-0.35(0.26)$ & $-0.66(0.34)$ & $0.14(0.15)$ & $-0.12(0.30)$ \\
\hline Nuts & $0.13(0.15)$ & $0.20(0.19)$ & $-0.11(0.08)$ & $-0.30(0.16)$ \\
\hline \multicolumn{5}{|l|}{ Non-alcoholic beverages } \\
\hline Tea & $-0.40(0.17)^{*}$ & $-0.57(0.22)^{*}$ & $0.07(0.10)$ & $-0.18(0.19)$ \\
\hline Coffee & $0.05(0.29)$ & $-0.49(0.37)$ & $0.03(0.16)$ & $0.57(0.32)$ \\
\hline Low calorie beverages & $-0.28(0.17)$ & $-0.26(0.22)$ & $0.006(0.10)$ & $0.002(0.19)$ \\
\hline High sugar beverages & $-0.17(0.12)$ & $0.23(0.16)$ & $0.005(0.07)$ & $-0.39(0.14)^{*}$ \\
\hline \multicolumn{5}{|l|}{$\begin{array}{l}\text { Frequency per week } \\
\text { Fried foods }\end{array}$} \\
\hline $\begin{array}{l}\text { Fried foods } \\
\text { Fried food at home }\end{array}$ & $-0.06(0.04)$ & $-0.15(0.05)^{*}$ & $0.05(0.02)^{*}$ & $0.05(0.04)$ \\
\hline Fried food away from home & $0.03(0.04)$ & $0.15(0.05)^{*}$ & $-0.08(0.02)^{* * *}$ & $-0.08(0.04)$ \\
\hline \multicolumn{5}{|c|}{$\begin{array}{l}\text { All estimates relative to consistently married; estimates for remarried are relative to consistently unmarried (that is, } \\
\text { divorced or widowed). †Adjusted for age in 1986, time period (1986-90, 1990-94), and the time varying } \\
\text { covariates of smoking (current compared with never or past smoker), alcohol intake (servings/week), body mass } \\
\text { index (kg } / \mathrm{m}^{2} \text { ), physical activity (METs/week), employment status (full time compared with part time, retired, or } \\
\text { disabled), history of hypertension, diabetes, high serum cholesterol, diagnosis of myocardial infarction, stroke, } \\
\text { cancer (except non-melanoma skin cancer), gastric or duodenal ulcer. }{ }^{*} \text { p value }<0.05 \text {; }{ }^{* * *} \text { p value }<0.001 \text {. }\end{array}$} \\
\hline
\end{tabular}

widowed men who remarried), based on comparability of effects as determined by likelihood ratio tests. Specific marital transitions and stable marital patterns were coded as indicator variables. We controlled for age in 1986, time period (1986-90; 1990-94), covariates that could potentially change health behaviour including employment status and medical diagnoses (hypertension, diabetes, and hypercholesterolaemia, history of myocardial infarction, stroke, gastric or duodenal ulcer, cancer (excluding non-melanoma skin cancer)), and when relevant, cigarette consumption, alcoholic beverage intake, BMI, physical activity, and total energy and fat intakes. Marital history and all covariates except age were modelled as time varying variables. Because the effects of marital transition on health behaviours may vary according to age, we conducted stratified analyses among men aged less than 65 years old $(n=31235)$, and men aged at least 65 years old $(n=7630)$ in 1986.

\section{RESULTS}

In table 1 , we present age adjusted characteristics, including dietary and other health behaviours, by marital status in 1986. The majority $(93.3 \%)$ of men were initially married, and of these men, $80.9 \%$ reported that they were married in 1994. At baseline, divorced men were most likely to smoke and drank more alcohol, but were also more active. In terms of diet, married men consumed more fruits and vegetables.

Figure 1 gives the results from multivariate analyses of relative change in cigarette and alcohol consumption by four year marital history. Among ever smokers in 1986, men who became divorced increased their daily consumption by 0.32 cigarettes relative to change in stably married men although the difference in trends was not significant $(p=0.18)$; this association was limited to men less than 65 years old who comprised the majority of divorce transitions. Men who remained divorced or widowed had decreased consumption compared with married counterparts $(-0.42$ cigarettes, $\mathrm{p}=0.0023)$. Decreased cigarette consumption over time was observed among younger and older unmarried men $(-0.40$ cigarettes, $p=0.015$ and -0.65 cigarettes, $p=0.0067$, respectively). Becoming widowed was associated with an increase of 0.51 servings of alcohol per week $(p=0.03)$, relative to change in men who stayed married; similar effects were observed among men aged less than 65 years old and men aged 65 years old or more. Becoming divorced was also modestly associated with an increase in alcohol consumption that was not statistically significant; as with cigarette consumption, this association was observed among younger men only in age stratified analyses. In contrast, men who remained unmarried decreased their weekly intake of alcoholic beverages by 0.21 servings $(p=0.051)$; both younger and older men who remained unmarried experienced decreases over time. In age stratified analyses, remarriage was associated with a non-significant decrease in alcohol consumption among younger men $(-0.41$ servings per week, $\mathrm{p}=0.065)$ but an increase among older men (1.28 servings, $\mathrm{p}=0.03$ ).

In Figure 2, we present adjusted relative change in BMI and physical activity for different four year marital histories. Men who became divorced or widowed had respective BMI decreases of $-0.31 \quad(p<0.0001)$ and $-0.35 \mathrm{~kg} / \mathrm{m}^{2}$ $(p<0.0001)$, relative to change in men who stayed married. 
Compared with men who remained unmarried, divorced and widowed men who remarried experienced increase in BMI $\left(0.25 \mathrm{~kg} / \mathrm{m}^{2}, \quad \mathrm{p}<0.0001\right)$ coupled with decreased level of physical activity $(-2.00 \mathrm{METs} /$ week, $\mathrm{p}=0.027)$. These effects on BMI and physical activity were observed in both age groups.

In multivariate analyses of four year change in dietary behaviour (table 2), men who became widowed decreased their weekly intake of vegetables by 2.91 servings $(p<0.0001)$. The decrease in vegetable intake associated with widowhood was more pronounced among younger than older men $(-4.22$ servings, $\mathrm{p}<0.0001$ compared with -1.73 servings, $p=0.034)$. Men who became divorced lowered their vegetable intake by 2.05 servings per week $(p<0.0001)$, compared with married men; the association was more pronounced among younger men. In additional analyses differentiating unmarried subgroups (that is, divorced or widowed), remarriage was particularly beneficial for widowers. For formerly widowed and divorced men, respective relative increases were $4.05(\mathrm{p}<0.0001)$ and 1.28 servings per week $(p=0.012)$. Remarriage among younger widowed men was associated with a larger increase in vegetable intake (4.63 servings, $\mathrm{p}=0.0003$ ) than remarriage among older widowers (3.32 servings, $\mathrm{p}=0.051$ ).

In terms of other dietary change (table 2), men who became widowed increased their frequency of eating fried foods away from home and decreased their consumption at home. They also increased their consumption of both organ meats and fish. Over time, men who experienced divorce had decreased consumption of fruits and poultry but also of red meats. Intake of refined grains and potatoes declined among men who became divorced or widowed, relative to change in married men. Consumption of whole grains, cereal, snacks, and sweets and desserts also decreased though declines were not generally significant. Remarriage seemed to have an overall salutary effect on diet, as suggested by increases in intake of vegetables and chicken and turkey in combination with relative decline in consumption of high sugar content beverages. However, men who remarried increased their intake of refined grains relative to men who did not remarry. Aside from a modest increase in snack consumption, dietary quality of unmarried men did not seem to worsen over time compared with the dietary quality of married men.

\section{DISCUSSION}

These longitudinal findings provide support for the hypothesis that marital termination is linked to adverse change in health behaviours. Alcohol consumption increased among men whose wives died. Former spouses suffered relative weight loss with marital break up. In contrast, men who remarried experienced increases in BMI along with decreases in physical activity compared with men who remained unmarried (that is, divorced or widowed). Loss of the marital relationship had detrimental effects on diet particularly in terms of decreased vegetable intake while remarriage was tied to increased vegetable consumption.

Among younger men, becoming widowed or divorced were each linked to more pronounced decrease in vegetable intake. Becoming divorced was also associated with increased cigarette and alcohol consumption among younger men although these latter relationships were not statistically significant and should be interpreted with caution.

\section{Previous research}

These results concur with previous reports linking marital dissolution with higher cigarette and alcohol consumption. ${ }^{23-35}$ In a national panel survey, men who became unmarried increased their cigarette consumption. ${ }^{35} \mathrm{~A}$ recent birth cohort study assessed marital status and drinking

\section{Key points}

- Marital termination may have an impact on health by adversely affecting health and dietary behaviours.

- Alcohol consumption increased among men whose wives died.

- Loss of the marital relationship had detrimental effects on diet particularly in terms of decreased vegetable intake while remarriage was linked to increased vegetable consumption.

habits at ages 23 and 33 years, and found that divorced men had twice the odds of heavy drinking as continuously married men; newly divorced men had even greater risks. ${ }^{23}$ It is probable that changes in both social support and stress levels underlie the observed relations with marital termination. Smoking and heavy drinking are each related to high levels of stress ${ }^{45}{ }^{46}$ and low social support. ${ }^{47}$ In fact, spousal support may buffer against stress ${ }^{48}$ and thereby lead to reductions in smoking and drinking. ${ }^{9}$ High levels of partner support have been prospectively associated with smoking cessation in treatment programmes. ${ }^{49}$ Although we did not have information on exact dates of transitions or duration of marital states, men who remained unmarried over four years reduced their use of alcohol and cigarettes relative to married men. Therefore, relative consumption may have increased because of the stress of initial marital break up, and then decreased over time, reflecting stabilisation.

Previous studies have also detected associations between marital break up and weight loss, as well as between marriage and weight gain. ${ }^{31-35}$ In a 10 year study of men aged 25-44 years at baseline, the risk of major weight loss nearly doubled with marital termination while the risk of major gain increased over threefold with marriage. ${ }^{31}$ In contrast with our hypothesis, remarriage was not linked to increased physical activity levels. Instead, formerly solitary men experienced relative decline along with weight gain upon remarrying. Time demands of a new spousal role may preclude routine exercise. ${ }^{12}$ Married life may also bring regularity to meal patterns, ${ }^{12}$ and increased food intake via social facilitation. ${ }^{50}$

Men who experience divorce or spousal death may lower intake of vegetables and other foods requiring preparation skills, and consume more convenience foods. We observed that marital termination led to substantial declines in vegetable intake. Noticeable improvements upon remarriage (for example, $>4$ servings/week for former widowers) strongly suggest a dietary advantage to wedlock, particularly for widowers. Our results are consistent with cross sectional studies that have reported poorer dietary quality for unmarried men. ${ }^{18-20}$ In a cross sectional study, Donkin et al found that solitary men aged 65 years and older have lower fruit and vegetable consumption compared with married counterparts (2.7 compared with 4.2 servings/day). ${ }^{18}$

In this study, becoming widowed or divorced were each associated with larger decline in vegetable intake among younger men. Such effect modification by age could be driven by hardy survivor characteristics moderating the effects of marital termination on behaviour within this cohort of health professionals. Alternatively, major life events noticeably divergent from the expected or normative life course (for example, early widowhood) may be associated with fewer available sources of social support. Effects of divorce according to age group should be interpreted with care as comparatively few divorce transitions occurred among older men $(\mathrm{n}=74)$. 


\section{Strengths and limitations of the study}

Based on repeated measures, the effects of marital transition were independent of key time varying confounders. Validation studies have found dietary and alcohol intake, BMI and physical activity levels to be accurately reported by the cohort. ${ }^{41-44}$ Self reports of smoking habit are generally accurate in population studies of adults. ${ }^{51}$ However, there are several limitations to our findings. Only $77.1 \%$ of the cohort provided marital status data for at least two consecutive time points. As serial non-respondents were more likely to be unmarried and have poorer health behaviours at baseline, it is plausible that non-respondents included a disproportionate number of men adversely affected by marital dissolution. Hence, loss to follow up may have biased effect estimates toward the null. While it is possible that newly divorced and bereaved men were less precise in reporting health behaviours, increased random error would merely inflate standard errors, and not affect point estimates. It seems unlikely that marital dissolution affected accuracy of self reported behaviours in a systematic way. We used marital status as a proxy measure for spousal support recognising that non-spousal cohabitating partners can provide similar support to unmarried men. As well, some men who reported being married may in fact be separated from their wives and live alone. Resulting non-differential misclassification would attenuate rather than exaggerate estimates. We used only incumbent marital status at four year intervals rather than interim changes to define marital transitions; any resulting misclassification would be random with respect to the outcome and lead to an underestimation of behaviour effects. We lacked information on psychological states such as depression that could potentially confound or mediate the association between marital history and change in health practices. However, if psychological health were in fact a mediator, controlling for its effects in multivariate analysis would not be appropriate. We cannot rule out the possibility that health behaviour, particularly alcohol use, led to marital transition. However, we did not find that health behaviours predicted marital transitions (data not shown). Finally, among our cohort of male health professionals of high socioeconomic status, we observed effect sizes of very modest magnitude. Men of lower income and education levels may experience more pronounced effects. ${ }^{20}$ Limits to generalisability apply to younger and older cohorts. Moreover, it is unclear whether effects may be particularly increased among older men of lower socioeconomic status. Generalisability limitations also apply to women who may be differentially affected.

\section{Conclusions}

Although linked to lowered intake of unhealthy starches, marital break up had a negative overall impact on healthful lifestyle. While comparatively modest effects were noted for individual behaviours (for example, alcohol consumption), aggregated effects on a range of health behaviours could appreciably affect health on a population level. The benefits of remarriage were most clearly related to dietary quality. Whereas dietary advantages may be obtained passively with cohabitation, positive modification of other lifestyle factors (for example, smoking) may involve slower and more complex motivational processes. As discussed, it is also likely that increased stress attributable to marital break up contributed to negative changes, most probably for cigarette and alcohol consumption. Future studies should collect information on levels of spousal support and stress to identify mechanisms. Furthermore, it should be emphasised that negative health behaviours do not fully explain the link between marital status and mortality ${ }^{52}$; other pathways including neuroendocrine mechanisms should be considered.
In summary, we conclude that marital termination may have an impact on health by adversely affecting a range of health and dietary behaviours in men. Clinicians and other health professionals should be attentive to marital transitions in their patients' lives as they could change diet and other health behaviours. Continued focus on the social context of health behaviour may improve the effectiveness of prevention and intervention programs. ${ }^{53}$ Studies of different combinations of age and socioeconomic groups, minorities, and women are needed to target public health efforts efficiently.

\section{Authors' affiliations}

P M Eng, Department of Epidemiology, Harvard School of Public Health, Boston, USA

I Kawachi, Department of Health and Social Behavior, Harvard School of Public Health, the Channing Laboratory, Department of Medicine, Brigham and Women's Hospital, and Harvard Medical School, Boston, USA

G Fitzmaurice, Department of Biostatistics, Harvard School of Public Health

E B Rimm, Departments of Epidemiology and Nutrition, Harvard School of Public Health, the Channing Laboratory, Department of Medicine, Brigham and Women's Hospital, and Harvard Medical School, Boston, USA

Funding: this study was supported by research grants HL 35464 and CA 55075 from the National Institutes of Health.

Conflicts of interest: none declared.

\section{REFERENCES}

1 Gove W. Sex, marital status, and mortality. Am J Sociol 1973;79:45-67.

2 Hu Y, Goldman N. Mortality differentials by marital status: an international comparison. Demography 1990;27:233-50.

3 Verbrugge LM. Marital status and health. J Marr Fam 1979;5:267-85.

4 Ebrahim S, Wannamethee G, McCallum A, et al. Marital status, change in marital status, and mortality in middle-aged British men. Am J Epidemiol 1995; 142:834-42.

5 Mendes De Leon CF, Kasl SV, Jacobs S. Widowhood and mortality risk in a community sample of the elderly: a prospective study. J Clin Epidemiol 1993;46:519-27.

6 Martikainen P, Valkonen T. Mortality after the death of a spouse: rates and causes of death in a large Finnish cohort. Am J Public Health 1996;86:1087-93.

7 Stroebe MS, Stroebe W. Who suffers more? Sex differences in health risks of the widowed. Psychol Bull 1983;93:279-301.

8 Tillgren $P$, Haglund BJA, Lundberg $M$, et al. The sociodemographic pattern of tobacco cessation in the 1980s: results from a panel study of living condition surveys in Sweden. J Epidemiol Community Health 1996;50:625-30.

9 Waldron I, Lye D. Family roles and smoking. Am J Prev Med 1989;5:136-41.

10 Broman C. Social relationships and health-related behavior. J Behav Med 1993; 16:335-50.

11 Luoto R, Poikolainen K, Uutela A. Unemployment, sociodemographic background and consumption of alcohol before and during the economic recession of the 1990s in Finland. Int J Epidemiol 1998;27:623-9.

12 Sobal J, Rauschenbach BS, Frongillo EA. Marital status, fatness and obesity. Soc Sci Med 1992;35:915-23.

13 Cairney J, Wade TJ. Correlates of body weight in the 1994 National Population Health Survey. Int J Obes Relat Metab Disord 1998;22:584-91.

14 Osler M. Social network and lifestyle in Danish adults. J Epidemiol Community Health 1995;49:327-8.

15 Schone BS, Weinick RM. Health-related behaviors and the benefits of marriage for elderly persons. Gerontologist 1998;38:618-27.

16 Shah M, Jeffery RW, Hannan PJ, et al. Relationship between sociodemographic and behavior variables, and body mass index in a population with high-normal blood pressure: Hypertension Prevention Trial. Eur J Clin Nutr 1989;43:583-96.

17 Braddon FE, Rodgers B, Wadsworth ME, et al. Onset of obesity in a 36 year birth cohort study. BMJ 1986;293:299-301.

18 Donkin AJ, Johnson AE, Lilley JM. Gender and living alone as determinants of fruit and vegetable consumption among the elderly living at home in urban Nottingham. Appetite 1998;30:39-51.

19 Billson H, Pryer JA, Nichols R. Variation in fruit and vegetable consumption among adults in Britain. An analysis from the dietary and nutritional survey of British adults. Eur J Clin Nutr 1999;53:946-52.

20 Davis MA, Randall E, Forthofer RN, et al. Living arrangements and dietary patterns of older adults in the United States. J Gerontol 1985;40:434-42.

21 Rosenbloom CA, Whittington FJ. The effects of bereavement on eating behaviors and nutrient intakes in elderly widowed persons. J Gerontol 1993;48:S223-9.

22 Shabar DR, Schultz R, Shabar H, et al. The effect of widowhood on weight change, dietary intake, and eating behavior in the elderly population. J Aging Health 2001;13:189-99. 
23 Power C, Rodgers B, Hope S. Heavy alcohol consumption and marital status: disentangling the relationship in a national study of young adults. Addiction 1999;94:1477-87.

24 Hajema K-J, Knibbe RA. Changes in social roles as predictors of changes in drinking behavior. Addiction 1998;93:1717-27.

25 Horwitz AV, White HR, Howell-White S. The use of multiple outcomes in stress research: a case study of gender differences in responses to marital dissolution. J Health Soc Behav 1996;37:278-91.

26 Chilcoat HD, Breslau N. Alcohol disorders in young adulthood: effects of transitions into adult roles. J Health Soc Behav 1996;37:339-49.

27 Leino EV, Ager CR, Fillmore KM, et al. A meta-analysis of multiple longitudinal studies from the Collaborative Alcohol-Related Longitudinal project. Am J Addict 1995;4:141-9.

28 Miller-Tutzaver C, Leonard KE, Windle M. Marriage and alcohol use: a longitudinal study of "maturing out". J Stud Alcohol 1991;52:434-40.

29 Romelsjo A, Lazarus NB, Kaplan GA, et al. The relationship between stressful life situations and changes in alcohol consumption in a general population sample. Br J Addict 1991;86:157-69.

30 Power C, Estaugh V. The role of family formation and dissolution in shaping drinking behavior in early adulthood. Br J Addict 1990;85:521-30.

31 Kahn HS, Williamson DF. The contributions of income, education and changing marital status to weight change among US men. Int J Obes 1990;14:1057-68.

32 Rissanen AM, Hellovaara M, Knekt $P$, et al. Determinants of weight gain and overweight in adult Finns. Eur J Clin Nutr 1991:45:419-30.

33 Sobal J, Rauschenbach B, Frongillo EA. Marital status changes and body weight changes: a US longitudinal analysis. Soc Sci Med 2001;56:1543-55.

34 Jeffrey RW, Rick AM. Cross-sectional and longitudinal associations between body mass index and marriage-related factors. Obes Res 2002;10:809-15.

35 Umberson D. Gender, marital status, and the social control of health behavior. Soc Sci Med 1992;34:907-17.

36 King AC, Kiernan M, Ahn DK, et al. The effects of marital transitions on changes in physical activity: results from a 10-year community study. Ann Behav Med 1998;20:64-9.

37 Umberson D. Family status and health behaviors: social control as a dimension of social integration. J Health Soc Behav 1987;28:306-19.

38 Joung IM, Stronks $\mathrm{K}$, van de Mheen $\mathrm{H}$, et al. Health behaviors explain part of the differences in self-reported health associated with partner/marital status in the Netherlands. J Epidemiol Community Health 1995;49:482-8.
39 Rimm EB, Giovannucci EL, Willett WC, et al. A prospective study of alcohol consumption and the risk of coronary disease in men. Lancet $1991 ; 338: 464-8$

40 Hu FB, Rimm EB, Smith-Warner SA, et al. Reproducibility and validity of dietary patterns assessed with a food frequency questionnaire. Am J Clin Nutr 1999:69:243-9.

41 Rimm EB, Giovannucci EL, Stampfer MJ, et al. Reproducibility and validity of an expanded self-administered semiquantitative food frequency questionnaire among male health professionals. Am J Epidemiol 1992;135:1114-26.

42 Giovannucci EL, Colditz GA, Stampfer MJ, et al. The assessment of alcohol consumption by a simple self-administered questionnaire. Am J Epidemiol 1991; 133:810-17.

43 Rimm EB, Stampfer MJ, Colditz GA, et al. Validity of self-reported waist and hip circumferences in men and women. Epidemiology 1990;1:466-73.

44 Chasan-Taber S, Rimm EB, Stampfer MJ, et al. Reproducibility and validity of a self-administered physical activity questionnaire for male health professionals. Epidemiology 1996;7:81-6.

45 National Institute on Alcohol Abuse and Alcoholism. Occupational alcoholism: a review of research, Research monograph no 8 . Washington, DC: US GPO, 1982.

46 Kleinke CL, Staneski RA, Meeker FB. Attributions for smoking behavior: comparing smokers with nonsmokers and predicting smokers' cigarette consumption. J Res Pers 1983;17:242-55.

47 Berkman LF, Syme SL. Social networks, host resistance and mortality: a nineyear follow-up study of Alameda county residents. Am J Epidemiol 1979; 109:186-204.

48 Cohen S, Wills TA. Stress, social support and the buffering hypothesis. Psychol Bull 1985;98:310-57.

49 Mermelstein R, Cohen S, Lichtenstein E, et al. Social support and smoking cessation and maintenance. J Consult Clin Psychol 1986;54:447-53.

50 De Castro JM. Family and friends produce greater social facilitation of food intake than other companions. Physiol Behav 1994;56:445-55.

51 Patrick DL, Cheadle A, Thompson DC, et al. The validity of self-reported smoking: a review and meta-analysis. Am J Public Health 1994;84:1086-93.

52 Berkman LF, Glass T. Social integration, social networks, social support, and health. In: Berkman LF, Kawachi I, eds. Social epidemiology. New York, NY: Oxford University Press, 2000:137-73.

53 Emmons KM. Health behaviors in a social context. In: Berkman LF, Kawachi I, eds. Social epidemiology. New York, NY: Oxford University Press, 2000:242-66. 